\title{
Editorial
}

\section{Killing Kyoto}

Tgnorance has never been an excuse in law, but politics clearly plays by different rules. By pretending that global warming simply isn't happening, President George W. Bush is clearly setting new standards for ostriches. Politicians all want to feature in the history books but Bush's ploy to be defender of the American people at all costs is positively breath-taking. Having provided lukewarm support for the Kyoto agreement before the election, to ensure he was not over-trumped by Al Gore, he has now apparently had a change of heart. It is hard to decide if this constitutes outright lying or simple everyday deceit. Apparently the 4000 scientists involved in the recent report by the Intergovernmental Panel on Climate Change and all those other countries that signed up to the Kyoto agreement must be wrong because the Bush advisors from the energy industry say that they are wrong. What world are these people living in?

In the Antarctic as well as around the rest of the world, scientists have put tremendous efforts and energy into attempting to resolve the complexities of global change. Understanding how our world functions is crucial to managing it properly in the future, so there is more than an academic interest in this research if we intend to continue to survive as a species. The recent paper by John Harries and his colleagues in Nature, looking at historical changes in longwave radiation as measured by satellites, is a confirmation that the model predictions are correct, however unwelcome that is to the US administration. Timescales for most changes at a global level are very long, from a political point of view ridiculously so, but scientists had hoped that politicians would recognise the early warning of future consequences and begin the long and difficult task of explaining the necessary changes to the voters. Worryingly, those in the US who have shown some concern about the cancellation of Kyoto - like the head of the Environmental Protection Agency and even Colin Powell at the State Department, have been sidelined and over-ruled. Indeed, the concerted attempts to open up the Alaskan Wildlife Refuge for oil extraction, suspend some of the laws on endangered species and set aside Clinton's protection orders on western forests simply underlines the new President's intention to ignore all of the environmental concerns with which the rest of the world is grappling.

Is the scientific community labouring in vain to document present changes and model the future? Should we simply assume that, as Bush has already said, America's policies will always be to put America's interests first regardless of the effects on the rest of the world? Will it now prove impossible to get the other signatories to Kyoto to honour their agreements, with the US bent on subverting any progress they might make? Will the US Administration now try to shut down those areas of environmental research that don't agree with current political dogma?

George Bush appears determined to lead the world towards disaster rather than sustainability. His views are still those of the Governor of Texas, a state noted for its high level of environmental damage and lack of concern for resource exploitation. Much easier for him to pick a fight with political enemies outside the USA, and cultivate xenophobia amongst the voters, than tackle the infinitely less palatable task of convincing his countrymen that they could and should set a positive example in managing the global environment. Or perhaps Bush is the only one prepared to recognize that, for most people, saving the environment means sacrifices by others rather than themselves. Are you willing to change your lifestyle radically or is it up to someone else to find a painless solution? Either way it is going to be a very long four years for those who worry about the future!

DAVID WALTON 